\title{
LIAN MALAI MADSEN. Fighters, Girls and Other Identities: Sociolinguistics in a Martial Arts Club. Bristol, U.K.: Multilingual Matters. 2015. 217 pp. Hb (9781783093984) £89.95.
}

\author{
Reviewed by MIGUEL PÉREZ-MILANS
}

At a time when the social sciences are revisiting some of the core assumptions and analytical toolkits with which migration has traditionally been approached (see Vertovec 2007), the study of urban contexts where migration at a large scale is a relatively new phenomenon provides an interdisciplinary point of focus. Important critiques have recently been made about some of the new terms that, as in the case of 'superdiversity', have resulted from this period of critical 'selfrevisionism' (Pavlenko 2016). Yet a careful examination of the situated experiences and daily practices of individuals and groups in such urban contexts warrants interrogation of the grand narratives about language, culture, territory, ethnicity and identity that have underpinned the discourses and policies on 'multiculturalism' and/or 'multilingualism' of the modern nationstate - and often with the ontological and epistemological complicity of the language disciplines (Blommaert and Rampton 2011; Arnaut et al. 2016).

Lian Malai Madsen's book addresses all of these concerns eloquently. By focusing on a group of multilingual adolescents at Nørrebro Taekwoondo Club in a Danish local neighbourhood with working-class and ethnic minority backgrounds, in the Copenhagen area, her data offer a captivating account of the ways in which official frames of migration, ethnicity and social inequity are inadequate. As Madsen shows, migration has been represented in Danish official policies and media reports as leading to the configuration of a culturally diverse society where the lack of social integration is seen as the reason why minority youth (particularly boys) end up investing in oppositional forms of peer-culture. This, in turn, is seen as resulting in academic under-achievement, weaker affiliation with the local labour market, and less participation in organised leisure activities among the so-called 'persons of an ethnic background different from Danish' (p. 4).

With this official frame of interpretation in mind, the path to tackling social inequity of ethnic minority youth in Denmark seems to be straightforward: if lack of social integration with the mainstream Danish society is the 'problem', then provision of opportunities for ethnic minority youth to engage in organised leisure activities and mingle with non-minority population is the solution. Thus, sports clubs enter the picture as a 'magical black box' that guarantees the integration of socially marginalised minority youngsters into the majority society. In other words, leisure sports are constructed as social spaces of co-existence that, under conditions of migration, help cushion the collision of two main cultural blocks, the majority and the minority, via allowing the minority to culturally adjust to the majority (p. 49).

In contrast to this coherent account - and the survey studies that support it - the book offers an alternative angle, one that involves a slow immersion into the social life of the martial arts club at which Madsen conducted her fieldwork. Drawing on the epistemological lens of linguistic ethnography, the author invites us to suspend the numerous assumptions behind the official rationale explained above, and to examine the ways in which actors build social relations, in the course of daily situated activities, through positioning themselves and others with respect to ideas, norms, linguistic practices and the types of social personae associated with ethnicrelated categories in the wider society. That is to say, the reader is encouraged to distance herself/himself from modernist narratives that present individual actors as emblems of static cultural groups, based on their (or their parents') passports; we are urged to take an empirical 
commitment to data with the aim of exploring which identities are made salient by whom, when, how, for what communicative purposes, and with what consequences in the constitution and negotiation of social relations.

The body of the book describes the emergence of these locally relevant identities at both interpersonal and institutional orders. But beyond just revealing fractures in the widely circulating discourses, such descriptions also feedback to existing literature in different fields, particularly in sociology of sports (p. 76) and sociolinguistics (p. 164). Chapter 2, 'Sports, Integration and Participation', provides a detailed ethnographic description of the overall social organisation of the martial arts club, with attention to the ways in which this social space is shaped by wider policies and the funding schemes of the Ministry of Integration that the club engages with. In particular, Madsen documents patterns regarding group relationships and characteristic practices of the different social groups involved, with the goal of identifying some of the most salient groups' identity positionings. In so doing, ethnographic data reveal the situated ways in which youngsters orient to Taekwondo, gender and age as key dimensions to membership status in the club community (p. 62). These data complicate official accounts, in which the mere act of registering minority youth counts as a statistical measure of social integration.

After introducing key concepts (Ch. 1) and the ethnographic context (Ch. 2), Chapters 3-5 constitute the core of the book's analytical contribution, followed by final perspectives in Chapter 6. In Chapter 3, 'Girls, Boys and Interaction', Madsen brilliantly describes the interactional enactment of gender identities in activities in which boys and girls orient differently towards peer relationships and group involvement. Her analysis reveals how the girls and the boys maintain and negotiate friendships in distinct ways. In the fourth and most important chapter, the author goes into the most sensitive aspect of the public discourses and policies related to youth, language and ethnic categorisation. With audio-recorded interactions as the key empirical base, Madsen demonstrates that the participants do not use contemporary urban speech style (i.e. linguistic features associated with heritage languages among ethnically mixed youth groups) primarily to signal ethnic identities. On the contrary, her participants perform this speech style, characterised by the incorporation into standard Danish of prosodic, phonetic and lexical patterns from Turkish, Kurdish and especially Arabic, in order to negotiate social status and situated forms of identity (e.g. toughness, authority and masculinity).

This evidence contradicts, Madsen argues, wider societal discourses (including those by sociolinguists) which tend to make sense of contemporary urban youth's linguistic practices by reference to ethnic identities. In fact, her participants also engage in the above-described linguistic practices to playfully exploit stereotypical ethnic identities in ways that 'challenge the social image of oppositional immigrant identity stereotypically associated with the use of several of the stylistic resources they employ' (p. 164). This strand of analysis is taken further in Chapter 5, the last empirical chapter. Against mainstream societal representations which highlight academic disengagement among ethnic minority youth in Copenhagen, Madsen shows how the boys in the club also orient towards academic identities. The enactment of these, in combination with non-standard linguistic features, happens to have symbolic value in the youngsters' playful negotiations of local social status within the peer group: though they orient towards school competence, 'what is valued among the older boys, in particular, is a non-nerdy academic approach to school work with focus on display of skills and achievements and a relaxed approach to official rules' (p. 180).

Attending to processes on a micro-scale that can inform conceptions of social integration, 
however, can be a daunting challenge for any linguistic ethnographer. At certain times, therefore, the analysis inevitably leaves the reader with the feeling of having very little understanding of who is who in the wider picture of the setting in which the fieldwork is carried out. Generally speaking, and in spite of the ample efforts at contextualising the situated practices under scrutiny, the description lacks an ethnographic account of the place that each of the analysed interactions have in the larger web of social relations that involve the participants. Indeed, many of the examples analysed across the book seem to have been extracted from an activity in which the youngsters produce posters as requested from Madsen, outside the training practice, plus a few examples self-recorded by the boys on their way to the Taekwondo club. Though these prove to be extremely rich in the context of Madsen's research concerns, one can't help wonder about how they fit into the context of each participant's trajectory of identification through the space/time of the social field under investigation (see Wortham 2006).

Comparatively little attention too, in light of the importance given to Bourdieu's field analysis in Chapter 2, goes to appreciating the weight of the institutional tensions faced by the club. While it is clear that the focus of the book is on the local negotiation of identities, this should not prevent us from reflecting on the lessons to be learned from the case of Nørrebro Taekwoondo Club as an institutional space vis-à-vis the wider social conditions of late modernity described in Chapter 4 (p. 162). The ethnographic analysis that Madsen delivers, regarding the institutional logic under which the club operates, has apparently been left out of the book's final conclusion. This concluding section could indeed have paid closer attention to the significance of the ways in which the club navigates the discursive space of the funding schemes that are made available by the State through the Ministry of Integration.

These critical remarks notwithstanding, this book is an eye-opener for sociolinguists interested in language use as a platform for the study of identity practices, ethnic categorisation, community sports and social integration. I would strongly recommend it for postgraduate students and researchers willing to embrace the uncomfortable feeling of having to make sense of linguistic practices without resorting automatically to taken-for-granted models of social organisation. I can't personally think of a better piece of work to illustrate what interrogating data means - versus just commenting on data.

\section{REFERENCES}

Arnaut, Karel, Jan Blommaert, Ben Rampton and Massimiliano Spotti (eds.). 2016. Language and Superdiversity. New York: Routledge.

Blommaert, Jan and Ben Rampton. 2011. Language and superdiversity. Diversities 13: 1-21.

Pavlenko, Aneta. In press. Superdiversity and why it isn't: Reflections on terminological innovation and academic branding. In Stephan Breidbach, Lutz Küster and Barbara Schmenk (eds.) Sloganizations in Language Education Discourse. Bristol, U.K.: Multilingual Matters.

Vertovec, Steven. 2007. Super-diversity and its implications. Ethnic and Racial Studies 30: 1024-1054.

Wortham, Stanton. 2006. Learning Identity: The Joint Emergence of Social Identification and Academic Learning. Cambridge, U.K.: Cambridge University Press.

MIGUEL PÉREZ-MILANS

Centre for Applied Linguistics

University College, London

m.milans@ucl.ac.uk 